\title{
Is there a difference in bleeding after left ventricular assist device implant: centrifugal versus axial?
}

Ann C. Gaffey ${ }^{1 *}$, Carol W. Chen ${ }^{1}$, Jennifer J. Chung ${ }^{1}$, Jason Han ${ }^{1}$, Christian A. Bermudez ${ }^{1}$, Joyce Wald ${ }^{2}$ and Pavan Atluri ${ }^{1}$

\begin{abstract}
Background: Continuous-flow left ventricular assist devices (CF-LVAD) have become the standard of care for patients with end stage heart failure. Device reliability has increased, bringing the potential for VAD, compared to transplant, into debate. However, complications continue to limit VADs as first line therapy. Bleeding is a major morbidity. A debate exists as to the difference in bleeding profile between the major centrifugal and axial flow devices. We hypothesized that there would be similar adverse bleeding event profiles between the 2 major CF-LVADs.

Methods: We retrospectively investigated isolated CF LVADs performed at our institution between July 2010 and July 2015: HeartMatell (HMII, $n=105)$ and HeartWare (HVAD, $n=34)$. We reviewed demographic, perioperative and short- and long-term outcomes.

Results: There was no significant difference in demographics or comorbidities. There was a low incidence of gastrointestinal $(\mathrm{Gl})$ bleed $3.9 \%$ in HMII and $2.9 \%$ in HVAD $(p=0.78)$. Preoperatively, the cohorts did not differ in coagulation measures $(p=0.95)$. Within the post-operative period, there was no difference in product transfusion: red blood cells $(p=0.10)$, fresh frozen plasma $(p=0.19)$, and platelets $(p=0.89)$. Post-operatively, a higher but not significantly different number of HMII patients returned to the operating room for bleeding $(n=27)$ compared to $\operatorname{HVAD}(n=6, p=0.35)$. There was no difference in rates of stroke $(p=0.65)$, re-intubation $(p=0.60)$, driveline infection $(p=0.05)$, and Gl bleeding $(p=0.31)$. The patients had equivalent ICU LOS $(p=0.86)$ and index hospitalization $\operatorname{LOS}(p=0.59)$.
\end{abstract}

Conclusion: We found no difference in the rate of bleeding complications between the current commercially available axial and centrifugal flow devices.

Keywords: Left ventricular assist device, Gastrointestinal bleeding

\section{Background}

During the past several decades, left ventricular assist devices (LVADs) have become a valuable and indispensable therapeutic option in the management of end stage heart failure. Recent data suggest that one of the most common adverse events within the first 30 days after LVAD implantation is bleeding in particular bleeding not requiring a return to the operating room [1-5]. Data

\footnotetext{
* Correspondence: Ann.gaffey@uphs.upenn.edu

${ }^{1}$ Division of Cardiovascular Surgery, Department of Surgery, Perelman School of Medicine, University of Pennsylvania, Silverstein 6, 3400 Spruce St, Philadelphia, PA 19104, USA

Full list of author information is available at the end of the article
}

from the Interagency Registry for Mechanically Assisted Circulatory Support (INTERMACS) have shown that the most frequent location of the first bleeding episode after implantation to be mediastinal (45\%), thoracic-pleural space (12\%), lower gastrointestinal (GI) tract (10\%), chest wall $(8 \%)$, and upper GI tract (8\%) with no difference in the overall bleeding rates between axial- and pulsatile flow devices [6].

The etiology of the greater rate of non-surgical bleeding is due to the relatively high non-physiological stress imparted on the blood components as they move through the device. Stress coupled with the reduced pulse pressure may result in the unanticipated 
increases in nonsurgical bleeding related to arteriovenous malformations (AVMs) in the GI tract. Bleeding specifically from the GI tract has been identified as the most common adverse event in implantation and is a major cause of morbidity in patients supported with LVAD therapy [7-10]. One of the proposed mechanisms for GI bleeding following implantation of an LVAD is acquired von Willebrand syndrome. Von Willebrand factor (vWF) is a protein expressed by vascular endothelial cells that is essential in preventing coagulopathy or bleeding; however, excessive cleavage of large vWF results in bleeding syndrome in the acquired syndrome as seen in patients with LVADs [11]. This paper aims to compare outcomes between axial (HeartMate II) and centrifugal (HeartWare) flow LVADs with respect to bleeding outcomes at a single institution.

\section{Methods}

\section{Study design}

All patients who underwent implantation of a CF-LVAD from July 2010 to July $2015(n=139)$ at the University of Pennsylvania were retrospectively reviewed. After initial data accrual, all patient identifiers were removed from the database. The University of Pennsylvania Institutional Review Board (IRB 7) approved this study for investigation.

Device selection was based on patient characteristics and surgeons' preference. Patients were initially not anti-coagulated on post-operative day zero. On postoperative day one, the patients were started on a heparin drip with a goal partial thromboplastin time of 45-50 s. Ultimately, all patients were anticoagulated with $325 \mathrm{mg}$ of aspirin and Coumadin to a target International Normalized Ratio (INR) of 2.0-3.0. No additional anti-platelet agents were used in either cohort.

Patient demographics, co-morbidities, laboratory values, and complications were retrospectively analyzed using our institutional database. Baseline information was collected the day before LVAD implantation. Patient demographic information and co-morbidities included age, sex, diabetes, etiology of cardiomyopathy, indication for LVAD, and INTERMACS patient profile risk score. Height and weight were collected in order to calculate body mass index (BMI). We also collected cardiopulmonary bypass time, days of mechanical ventilation, duration of hospital stay, and ICU length of stay.

Patients were followed on LVAD support for complications and intraoperative outcomes out to 36 months. Potential device related complications included: GI bleeding, infection, right ventricular failure, stroke, VAD malfunction, and wound infection. We defined GI bleeding by hematemesis, melena, or active bleeding at the time of endoscopy or colonoscopy. All complications were recorded during ICU stay except for device malfunction, GI bleeding, and death, which were also followed after discharge.

\section{Outcomes analysis}

The primary outcomes were post-operative bleeding events. Secondary outcomes included postoperative complications and length of stay outcomes. Normally distributed variables were presented as mean value \pm standard deviation; nonnormally distributed were presented as median value with interquartile range. Normality of all data variables was tested. Non-parametric data was analyzed using KruskalWallis one way analysis of variance and parametric data was analyzed by a two-sample t-test. Significance was set at $\alpha=0.05$. All statistical analyses were performed using commercially available software (STATA 13.1; Statacorp LP, College Station, Texas).

\section{Results}

\section{Patient characteristics}

During the study time frame, 105 HMII implants and 34 HVAD implants were performed at our institution. Between the two cohorts, no difference existed with regard to age $(p=0.83)$ and gender with the majority of patients being male $(p=0.73$, Table 1$)$. The most common indication for LVAD implantation in both groups was destination therapy with $59.1 \%$ in the HMII cohort and $52.9 \%$ in the HVAD cohort $(p=0.89)$. The second indication for LVAD implantation was bridge to transplantation in $26.7 \%$ of the HMII cohort and $35.3 \%$ in the HVAD cohort. There was no difference in INTERMACS classification between the two cohorts $(p=0.19)$ with the greatest percentage in both being class 2 with $37.1 \%$ in HMII and $41.2 \%$ in HVAD.

In terms of past medical history, there was a low frequency of GI bleeding in both cohorts at less than $4 \%$

Table 1 Baseline characteristics of patients implanted with the HeartMate II (HMII) and HeartWare (HVAD)

\begin{tabular}{llll}
\hline & HMII $(n=105)$ & HVAD $(n=34)$ & $p$-value \\
\hline Age & $56.5+13.9$ & $57.2+14.6$ & 0.82 \\
Sex male, $\mathrm{n}(\%)$ & $83(79.1)$ & $27(81.8)$ & 0.73 \\
Body mass index & $29.2+6.8$ & $29.5+6.2$ & \\
LVAD Indication, $\mathrm{n}(\%)$ & & & 0.89 \\
$\quad$ Bridge to transplantation & $28(26.7)$ & $12(35.3)$ & \\
$\quad$ Destination therapy & $62(59.1)$ & $18(52.9)$ & \\
Bridge to decision & $13(12.4)$ & $1(2.9)$ & \\
$\quad$ Bridge to recovery & $2(1.9)$ & $3(8.8)$ & \\
INTERMACS Classification & & & \\
1 & $12(14.3)$ & $5(14.7)$ & \\
2 & $39(37.1)$ & $14(41.2)$ & \\
3 & $36(34.3)$ & $15(44.1)$ & \\
4 & $14(13.3)$ & & 0.59 \\
\hline 5 & $1(0.9)$ & & \\
Heart failure duration, months & $2.2+1.1$ & $2.3+0.8$ & \\
\hline
\end{tabular}


$(p=0.78)$. For all other past medical history, there was no difference with regards to coronary artery disease $(p=0.53)$, hypertension $(p=0.76)$, atrial fibrillation $(p=0.82)$ and chronic renal insufficiency $(p=0.60)$. The etiology of heart failure was similar between the groups, with ischemic and idiopathic being the two most common causes $(p=0.59)$ (Table 2).

\section{Intraoperative outcomes}

For the HMII cohorts, $21 \%$ of the patients were redosternotomy compared to $30 \%$ in the HVAD $(p=0.31)$. The cardiopulmonary bypass time $(85.1 \pm 37.7$ vs. $81.8 \pm 47.9 \mathrm{~min}, p=0.72$ ) was low and similar in the cohorts. Additionally, there was no difference in blood product transfusion between the two groups (Table 3).

\section{Post-operative outcomes}

Within the HVAD cohort, there was a higher requirement for temporary RVAD at $29 \%$ compared to $15 \%$ in HMII $(p=0.02)$. There was no difference in immediate

Table 2 Pre-implantation past medical history, heart failure, etiology, and laboratory values of patients implanted with the HeartMate II (HMII) and HeartWare (HVAD)

\begin{tabular}{|c|c|c|c|}
\hline & $\begin{array}{l}\mathrm{HMII} \\
(n=105)\end{array}$ & $\begin{array}{l}\text { HVAD } \\
(n=34)\end{array}$ & $p$-value \\
\hline \multicolumn{4}{|l|}{ Past medical history, $n$ (\%) } \\
\hline $\begin{array}{l}\text { History of gastrointestinal } \\
\text { bleeding }\end{array}$ & $4(3.9)$ & $1(2.9)$ & 0.78 \\
\hline Coronary artery disease & $49(46.7)$ & $18(53.0)$ & 0.53 \\
\hline Diabetes mellitus & $48(45.7)$ & $14(41.2)$ & 0.65 \\
\hline Smoking & $38(36.2)$ & $22(66.7)$ & 0.002 \\
\hline Hypertension & $55(52.9)$ & $19(55.9)$ & 0.76 \\
\hline Atrial fibrillation & $44(41.9)$ & $15(44.1)$ & 0.82 \\
\hline Cerebral vascular accident & $13(12.4)$ & $3(8.8)$ & 0.55 \\
\hline Chronic renal insufficiency & $37(35.2)$ & $10(30.3)$ & 0.60 \\
\hline Heart failure etiology, $n(\%)$ & & & 0.59 \\
\hline Ischemic & $47(45.2)$ & $12(55.2)$ & \\
\hline Idiopathic & $45(43.3)$ & $10(34.5)$ & \\
\hline Viral & $1(1.0)$ & - & \\
\hline Peripartum & $4(3.9)$ & $1(3.5)$ & \\
\hline Alcoholic & $1(1.0)$ & - & \\
\hline Myocarditis & $1(1.0)$ & $2(6.9)$ & \\
\hline $\begin{array}{l}\text { Chemotherapy Induced } \\
\text { cardiomyopathy }\end{array}$ & $2(1.9)$ & - & \\
\hline Vavlular & $3(2.9)$ & - & \\
\hline \multicolumn{4}{|l|}{ Lab values } \\
\hline White blood cell (THO/uL) & $8.9+4.9$ & $7.9-2.5$ & 0.15 \\
\hline Hemoglobin (g/dL) & $12.0+0.9$ & $10.8+0.4$ & 0.23 \\
\hline Platelet (THO/uL) & $184.9+69.8$ & $191.9+83.4$ & 0.66 \\
\hline Prothrombin Time (seconds) & $52.6+2.5$ & $52.3+3.9$ & 0.95 \\
\hline
\end{tabular}

Table 3 Intraoperative outcomes and product utilization of patients implanted with the HeartMate II (HMII) and HeartWare (HVAD)

\begin{tabular}{llll}
\hline & HMII $(n=105)$ & $\operatorname{HVAD}(n=34)$ & $p$-value \\
\hline Redo sternotomy, $n(\%)$ & $22(21)$ & $10(30)$ & 0.31 \\
$\begin{array}{l}\text { Cardiopulmonary bypass time, } \\
\text { minutes }\end{array}$ & $85.1+37.7$ & $81.8+47.9$ & 0.72 \\
$\begin{array}{l}\text { Product Transfusion, peri-operative (72 h) } \\
\quad\end{array}$ & \\
$\quad$ Red blood cells, units & $8.2+1.0$ & $4.9+1.6$ & 0.10 \\
$\quad$ Fresh frozen plasma, units & $3.3+0.5$ & $2.0+0.6$ & 0.19 \\
$\quad$ Platelets, units & $1.1+0.2$ & $1.2+0.5$ & 0.89 \\
\hline
\end{tabular}

post-operative day one laboratory values with regards to hemoglobin $(9.9 \pm 1.5$ vs. $9.7 \pm 1.8 \mathrm{~d} / \mathrm{dL}, p=0.63)$ and international normalized ratio $(1.4 \pm 0.3$ vs. $1.3 \pm 0.1$, $p=0.06$ ); however, partial thromboplastin time was greater in the HVAD compared to HMII $(34.7 \pm 9.3$ vs. $40.1 \pm 8.4 \mathrm{~s}, p=0.003$ ).

Prior to return to possible return the operating room, hemodynamics were measured as included in Table 4. Mean arterial pressure was equivalent between the two cohorts (72 \pm 11 vs. $68 \pm 9 \mathrm{mmHg}, p=0.29$ ). As surrogate marker of right ventricular function, central venous pressure was noted to be elevated within the HVAD compared to the HMII cohort $(10 \pm 3$ vs. $13 \pm 2 \mathrm{mmHg}$, $p=0.05)$. Additionally, the cardiac index was reduced in the HVAD cohort compared to HMII $(2.5 \pm 1.1$ vs. $2.2+$ $\left.1.3 \mathrm{~L} / \mathrm{min} / \mathrm{m}^{2}, p=0.04\right)$.

Within the index hospitalization, there was a higher but not significantly different incidence of intra-thoracic bleeding requiring operative exploration within the HMII compared to the HVAD cohort $(25.7 \%$ vs. $18.2 \%$, $p=0.35$ ). The rate of GI bleeding within the index hospitalization was similar between the two groups $(11.5 \%$ vs. $5.9 \%, p=0.28)$. Throughout follow-up, there was no difference between GI bleeding at $3,12,24$, and 36 months ( $p=0.35,0.45,0.48$, and 0.23 , respectively).

As shown in Fig. 1, there was no difference in postVAD implantation survival between the two cohorts (log rank $p=0.0769)$.

\section{Discussion}

Balancing bleeding and thrombotic complications has become a difficult clinical dilemma, made more challenging by the poorly understood difference in risk factors. This study showed that overall, patients had similar outcomes with regards to bleeding, irrespective of whether they received a HMII or HVAD and there was no difference in associated mortality.

Overall, the patient cohorts were similar with regard to pre-operative conditions. The only significant difference between the two cohorts was nearly a one third greater incidence of smoking within the HVAD cohort 
Table 4 Postoperative outcomes for patients implanted with the HeartMate II (HMII) and HeartWare (HVAD)

\begin{tabular}{|c|c|c|c|}
\hline & HMII $(n=105)$ & $\operatorname{HVAD}(n=34)$ & $p$-value \\
\hline $\begin{array}{l}\text { Temporary RVAD Requirement, } \\
n(\%)\end{array}$ & $16(15)$ & $10(29)$ & 0.02 \\
\hline Time to extubation, days & $1.5(1,5)$ & $2(1.5)$ & 0.63 \\
\hline ICU length of stay, days & $7(4,14)$ & $8(6,15)$ & 0.86 \\
\hline Hospital length of stay, days & $20(14,32)$ & $20(15,27)$ & 0.59 \\
\hline \multicolumn{4}{|l|}{ Post-operative day one lab values } \\
\hline White blood cells (THO/uL) & $15.6+6.7$ & $15.5+5.7$ & 0.96 \\
\hline Hemoglobin (d/dL) & $9.9+1.5$ & $9.7+1.8$ & 0.63 \\
\hline Platelet (THO/uL) & $138.1+52.6$ & $147.7+57.9$ & 0.39 \\
\hline International normalized ratio & $1.4+0.3$ & $1.3+0.1$ & 0.06 \\
\hline Prothrombin time (seconds) & $34.7+9.3$ & $40.1+8.4$ & 0.003 \\
\hline $\begin{array}{l}\text { Lactic acid dehydrogenase } \\
(\mathrm{U} / \mathrm{L})\end{array}$ & $499.8+228.1$ & $411.6+96.1$ & 0.14 \\
\hline \multicolumn{4}{|l|}{ Hemodynamics } \\
\hline $\begin{array}{l}\text { Mean Arterial Pressure } \\
(\mathrm{mmHg})\end{array}$ & $72+11$ & $68+9$ & 0.29 \\
\hline $\begin{array}{l}\text { Central Venous Pressure } \\
(\mathrm{mmHg})\end{array}$ & $10+3$ & $13+2$ & 0.05 \\
\hline $\begin{array}{l}\text { Systolic Pulmonary Artery } \\
\text { Pressure }(\mathrm{mmHg})\end{array}$ & $28+4$ & $26+6$ & 0.07 \\
\hline Cardic Index $\left(\mathrm{L} / \mathrm{min} / \mathrm{m}^{2}\right)$ & $2.5+1.1$ & $2.2+1.3$ & 0.04 \\
\hline \multicolumn{4}{|c|}{ Complications- index hospitalization, $n(\%)$} \\
\hline Intra-thoracic bleeding & $27(25.7)$ & $6(18.2)$ & 0.35 \\
\hline Stroke & $4(3.8)$ & $2(5.9)$ & 0.65 \\
\hline Re-intubation & $20(19.1)$ & $5(15.2)$ & 0.6 \\
\hline Drive line infection & $2(3.9)$ & $0(0.0)$ & 0.05 \\
\hline \multicolumn{4}{|l|}{ Gastrointestinal bleeding, $n$ (\%) } \\
\hline Index hospitalization & $12(11.5)$ & $2(5.9)$ & 0.28 \\
\hline 3 months & $17(19.5)$ & $3(11.5)$ & 0.35 \\
\hline 12 months & $8(16.33)$ & $0(0.0)$ & 0.54 \\
\hline 24 months & $3(15.0)$ & $0(0.0)$ & 0.48 \\
\hline 36 months & $3(15.0)$ & $0(0.0)$ & 0.23 \\
\hline
\end{tabular}

compared the HMII; however, this pre-operative difference did not translate into a difference in post-operative outcomes. Both groups had a low incidence of prior GI bleeding and with no significant difference in pre-implant coagulation factors. During the operation, and within 30 days post-operatively, there was a low blood product requirement without any difference between the two cohorts.

Post-operatively, a greater percentage of the HVAD cohort required temporary RVAD support. This finding is supported by the reduced right ventricular function within the HVAD cohort immediately prior to RVAD implantation. The CVP was noted to be significantly elevated within the HVAD cohort suggesting right heart strain. The incidence of right ventricular support was higher than that reported in the ADVANCE trial at $2.1 \%$ requiring mechanical support and $12.1 \%$ on inotropic support [12]. Given that there are no significant differences pre-operatively and intra-operatively between the two groups, it seems as though this difference is likely attributed to small numbers in both cohorts. Overall, both the HMII and HVAD patients had nearly equivalent time to extubation, ICU length of stay, and hospital length of stay.

Furthermore, the incidence of post-operative complications was low between both groups. Examining the implantation technique between the devices, the HMII requires creation and tunneling of subcutaneous pocket while the HVAD has a smaller dissection for the intrapericardial implantation. Despite the differences in technique, no difference existed in overall bleeding events. This similar outcome between the two groups suggests that a meticulous dissection of the pump pocket, as well as hemostasis, is essential to keep bleeding events low for those patients receiving HMII. Additionally, the rate of intra-thoracic bleeding requiring a return to the operating room for a washout was similarly low between the groups. These low rates are further supported by those of the ADVANCE trial with risk of 0.26/patient-year in the HVAD and 0.45/patient-year for the HMII [12].

Furthermore, numerous studies have been published showing that the incidence of GI bleeding after LVAD implantation to vary between 18 and 40\% [13-15]. GI bleeding after implantation is classified as upper GI bleeding (proximal to the ligament of Trietz) or lower GI bleeding (distal to the ligament of Trietz). Most common causes are vascular malformations like AVMs and Dieulafoy lesions, which account for $30-40 \%$ and 15-20\%, respectively [16]. Within our study, the rates of GI bleeding we reported in both cohorts are similar to past studies which reported rates between $11 \%$ and $13 \%$ [17-19] in the HVAD cohort and 22\% in HMII patients [20]. During the index hospitalization only $11.5 \%$ of HMII and 5.9\% HVAD experienced GI bleeding in our cohort of patients. Throughout follow up there was no difference in the occurrence of a GI bleed between the cohorts out to 36 months of follow-up.

The etiology of the GI bleeding following LVAD implantation is multifactorial given the need for chronic anticoagulation as well as the changes in systemic immunologic and thrombostatic functions [21]. One proposed mechanism of GI bleeding is acquired von Willebrand syndrome due to the fragmentation of high molecular weight multimers of vWF. A study by Meyer et al. [22] demonstrated a reduction in high molecular weight vWF in HVAD patients. This finding suggest that although HVAD shear forces are low due to the contact free design and lower revolutions per minute in the HVAD, the shear force still reaches a 


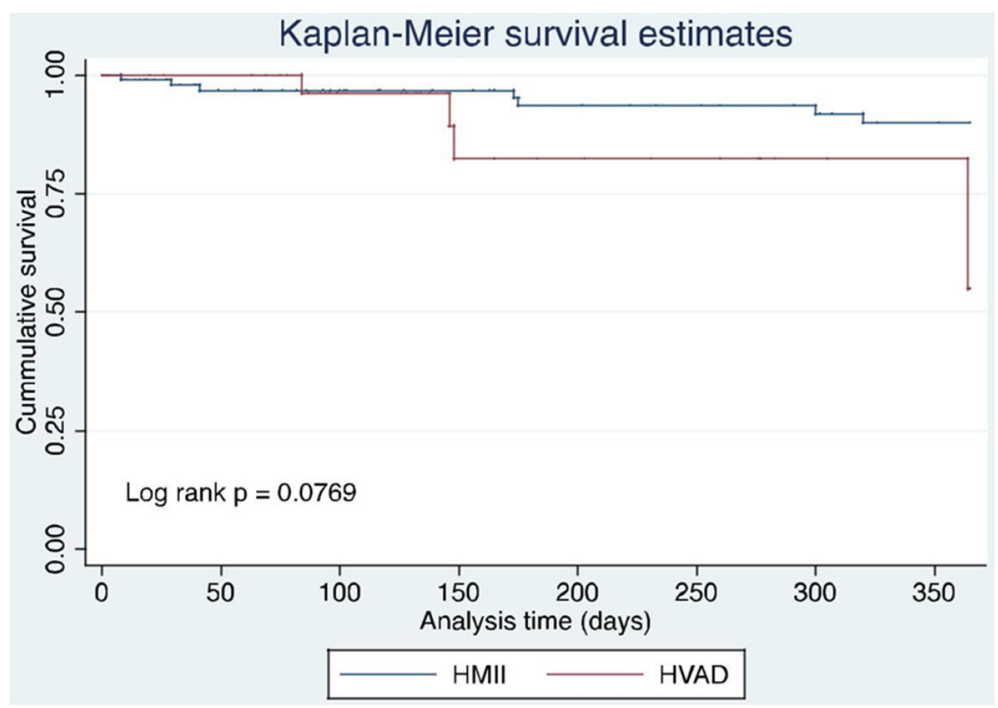

Fig. 1 Kaplan Meier survival curve for patients following HMII and HVAD implantation

sufficient threshold to induce vWF unfolding [23]. As result, that both HMII and HVAD patients develop acquired von Willebrand syndrome, it is anticipated that they would have similar rates of GI bleeding.

For management of an LVAD patient with GI bleeding, a multidisciplinary approach is needed involving possible reversal of anticoagulation, holding of anticoagulants, and possible medical and surgical interventions. Overall, the main goals are to locate the bleeding source and the severity by holding anti-coagulation and resuscitation to maintain stable hemodynamics.

\section{Conclusions}

Overall, balancing bleeding and thrombosis risks continues to be a critical component of LVAD patient management moving forward, especially with the advent of novel anticoagulant agents. Our study further adds to the literature that the rate of bleeding between axial and centrifugal pumps is low without significant difference between the two.

\section{Limitations}

Limitations of this study include its retrospective nature. Due to sample size restrictions, we were unable to perform adjusted analysis. Furthermore, the small sample sized may have limited the study's ability to detect statistically significant differences in some of the variables compared. The value of transthoracic echocardiogram within the immediate postoperative period is difficult to gain value given the obscure windows, as a result, cardiac index provides a better measurement of function. Additionally, although we did not observe high INR before GI bleeding events, some of the incidences may have been precipitated by high INR in patients.

\section{Abbreviations}

AVMS: Arteriovenous malformations; CF-LVAD: Continuous-flow left ventricular assist devices; Gl: Gastrointestinal; HMII: HeartMate II; HVAD: HeartWare; INR: International normalized ratio; INTERMACS: Interagency Registry for Mechanically Assisted Circulatory Support; LVAD: Left ventricular assist device; WWF: Von Willebrand factor (VWF)

\section{Acknowledgments}

Not applicable

\section{Availability of data and materials}

United Network of Organ Sharing Database is publically available through the following website: https://optn.transplant.hrsa.gov/data/request-data/.

\section{Authors' contributions}

AG conceived of the study, and participated in its design, coordination, and drafted the manuscript. CC participated in the design of the study and performed the statistical analysis. JC and JH performed statistical analysis and assisted with drafting of the manuscript. CB, JW, and PA conceived of the study, and participated in its design and coordination and helped to draft the manuscript. All authors read and approved the final manuscript.

Ethics approval and consent to participate

The University of Pennsylvania Institutional Review Board (IRB 7) approved this study for investigation.

Consent for publication

Not applicable

\section{Competing interests}

The authors declare that they have no competing interests.

\section{Publisher's Note}

Springer Nature remains neutral with regard to jurisdictional claims in published maps and institutional affiliations.

\section{Author details}

'Division of Cardiovascular Surgery, Department of Surgery, Perelman School of Medicine, University of Pennsylvania, Silverstein 6, 3400 Spruce St, Philadelphia, PA 19104, USA. ²Division of Cardiology, Department of Medicine, Perelman School of Medicine, University of Pennsylvania, Philadelphia, USA. 
Received: 31 July 2017 Accepted: 22 January 2018

Published online: 13 February 2018

\section{References}

1. Slaughter MS, Rogers JG, Milano CA, et al. Advanced heart failure treated with continuous-flow left ventricular assist device. N Engl J Med. 2009. 361(23):2241-51. https://doi.org/10.1056/NEJMoa0909938.

2. Genovese EA, Dew MA, Teuteberg JJ, et al. Incidence and patterns of adverse event onset during the first 60 days after ventricular assist device implantation. Ann Thorac Surg. 2009;88(4):1162-70. https://doi.org/10.1016/j. athoracsur.2009.06.028.

3. Pagani FD, Miller LW, Russell SD, et al. Extended mechanical circulatory support with a continuous-flow rotary left ventricular assist device. J Am Coll Cardiol. 2009;54(4):312-21. https://doi.org/10.1016/j.jacc.2009.03.055.

4. Uriel N, Pak S-W, Jorde UP, et al. Acquired von Willebrand syndrome after continuous-flow mechanical device support contributes to a high prevalence of bleeding during long-term support and at the time of transplantation. J Am Coll Cardiol. 2010;56(15):1207-13. https://doi.org/10.1016/j.jacc.2010.05.016.

5. Pal JD, Piacentino V, Cuevas AD, et al. Impact of left ventricular assist device bridging on posttransplant outcomes. Ann Thorac Surg. 2009;88(5):1457-61; discussion 1461. https://doi.org/10.1016/j.athoracsur.2009.07.021.

6. Jessup ML, Goldstein D, Ascheim DD, et al. 5 risk for bleeding after MCSD implant: an analysis of 2358 patients in INTERMACS. J Hear Lung Transplant. 2011;30(4) https://doi.org/10.1016/j.healun.2011.01.012.

7. Stern DR, Kazam J, Edwards P, et al. Increased incidence of gastrointestinal bleeding following implantation of the HeartMate II LVAD. J Card Surg. 2010;25(3):352-6. https://doi.org/10.1111/j.1540-8191.2010.01025.x.

8. Stulak JM, Mehta V, Schirger JA, et al. Temporal Differences in Causes of Mortality After Left Ventricular Assist Device Implantation. Ann Thorac Surg. 2015;99(6):1969-74. https://doi.org/10.1016/j.athoracsur.2015.01.036.

9. Geisen U, Heilmann C, Beyersdorf F, et al. Non-surgical bleeding in patients with ventricular assist devices could be explained by acquired von Willebrand disease. Eur J Cardiothorac Surg. 2008;33(4):679-84. https://doi. org/10.1016/j.ejcts.2007.12.047.

10. Crow S, John R, Boyle A, et al. Gastrointestinal bleeding rates in recipients of nonpulsatile and pulsatile left ventricular assist devices. J Thorac Cardiovasc Surg. 2009;137(1):208-15. https://doi.org/10.1016/j.jtcvs.2008.07.032.

11. Suarez J, Patel CB, Felker GM, Becker R, Hernandez AF, Rogers JG. Mechanisms of bleeding and approach to patients with axial-flow left ventricular assist devices. Circ Heart Fail. 2011;4(6):779-84. https://doi.org/10.1161/CIRCHEARTFAILURE.111.962613.

12. Aaronson KD, Slaughter MS, Miller LW, et al. Use of an intrapericardial, continuous-flow, centrifugal pump in patients awaiting heart transplantation. Circulation. 2012;125(25):3191-200. https://doi.org/10.1161/ CIRCULATIONAHA.111.058412.

13. John R, Kamdar F, Eckman $P$, et al. Lessons learned from experience with over 100 consecutive HeartMate II left ventricular assist devices. Ann Thorac Surg. 2011;92(5):1593-9; discussion 1599-1600. https://doi.org/10.1016/j. athoracsur.2011.06.081.

14. Morgan JA, Paone G, Nemeh HW, et al. Gastrointestinal bleeding with the HeartMate II left ventricular assist device. J Heart Lung Transplant. 2012; 31(7):715-8. https://doi.org/10.1016/j.healun.2012.02.015.

15. Aggarwal A, Pant R, Kumar $S$, et al. Incidence and management of gastrointestinal bleeding with continuous flow assist devices. Ann Thorac Surg. 2012;93(5):1534-40. https://doi.org/10.1016/j.athoracsur.2012.02.035.

16. Demirozu ZT, Radovancevic R, Hochman LF, et al. Arteriovenous malformation and gastrointestinal bleeding in patients with the HeartMate II left ventricular assist device. J Heart Lung Transplant. 2011;30(8):849-53. https://doi.org/10.1016/j.healun.2011.03.008.

17. Wieselthaler GM, Gerry O, Jansz P, Khaghani A, Strueber M. Initial clinical experience with a novel left ventricular assist device with a magnetically levitated rotor in a multi-institutional trial. J Heart Lung Transplant. 2010; 29(11):1218-25. https://doi.org/10.1016/j.healun.2010.05.016.

18. Miller LW, Pagani FD, Russell SD, et al. Use of a Continuous-Flow Device in Patients Awaiting Heart Transplantation. N Engl J Med. 2007;357(9):885-96. https://doi.org/10.1056/NEJMoa067758.

19. Popov AF, Hosseini MT, Zych B, et al. Clinical experience with HeartWare left ventricular assist device in patients with end-stage heart failure. Ann Thorac Surg. 2012;93(3):810-5. https://doi.org/10.1016/j.athoracsur.2011.11.076.

20. Demirozu ZT, Radovancevic R, Hochman LF, et al. Arteriovenous malformation and gastrointestinal bleeding in patients with the HeartMate
II left ventricular assist device. J Hear Lung Transplant. 2011;30(8):849-53. https://doi.org/10.1016/j.healun.2011.03.008.

21. John R, Lee $\mathrm{S}$. The biological basis of thrombosis and bleeding in patients with ventricular assist devices. J Cardiovasc Transl Res. 2009;2(1):63-70. https://doi.org/10.1007/s12265-008-9072-7.

22. Meyer AL, Malehsa D, Budde U, Bara C, Haverich A, Strueber M. Acquired von Willebrand syndrome in patients with a centrifugal or axial continuous flow left ventricular assist device. JACC Heart Fail. 2014;2(2):141-5. https://doi.org/10.1016/j.jchf.2013.10.008.

23. Crow SS, Joyce DD. Are centrifugal ventricular assist devices the answer to reducing post-implantation gastrointestinal bleeding? JACC Heart Fail. 2014; 2(2):146-7. https://doi.org/10.1016/j.jchf.2013.11.008.

\section{Submit your next manuscript to BioMed Central and we will help you at every step:}

- We accept pre-submission inquiries

- Our selector tool helps you to find the most relevant journal

- We provide round the clock customer support

- Convenient online submission

- Thorough peer review

- Inclusion in PubMed and all major indexing services

- Maximum visibility for your research

Submit your manuscript at www.biomedcentral.com/submit
Biomed Central 